\title{
Oxygen sensing in the hypoxic response pathway: regulation of the hypoxia-inducible transcription factor
}

\author{
Richard K. Bruick ${ }^{1}$ \\ Department of Biochemistry, University of Texas Southwestern Medical Center, Dallas, Texas 75390-9152, USA
}

Oxygen occupies a central role in the maintenance of life as we know it, perhaps most prominently in aerobic metabolism, where $\mathrm{O}_{2}$ serves as the terminal electron acceptor in oxidative phosphorylation. However, oxygen transport by simple diffusion becomes limiting as organisms become larger and more active. To maintain oxygen homeostasis, higher eukaryotes have adopted specialized mechanisms to enhance $\mathrm{O}_{2}$ uptake and distribution. The resulting respiratory and circulatory systems are dynamic, capable of responding to changes in oxygen availability on either a local or organismal level. Though some oxygen-dependent responses rely on the activity of specialized oxygen-sensing cells, conserved oxygen-responsive pathways are expressed in almost every mammalian cell. In fact, this ability of individual cells to sense and respond to changes in oxygen availability is critical for many developmental, physiological, and pathological processes. Unlike the rapid responses to changes in oxygen availability, which can be mediated through posttranslational modifications or membrane depolarization (for review, see López-Barneo et al. 2001), this ubiquitous hypoxic response pathway involves changes in gene expression that occur over several hours. These changes are mediated in part through the induction of hypoxia-inducible transcription factors, the regulatory components of which can also be found in simpler eukaryotes such as fruit flies and nematodes.

\section{Hypoxia-inducible factor is regulated by oxygen availability}

In mammalian cells, exposure to a low-oxygen environment triggers a hypoxic response pathway centered on the regulated expression of the hypoxia-inducible transcription factor (HIF). Initially purified via its affinity for the mapped hypoxia-responsive element (HRE) within the promoter of the erythropoietin (Epo) gene (Wang and Semenza 1995; Wang et al. 1995a), HIF has since been

\footnotetext{
${ }^{1}$ Correspondence.
}

E-MAIL bruick@biochem.swmed.edu; FAX (214) 648-3346.

Article and publication are at http://www.genesdev.org/cgi/doi/10.1101/ gad.1145503. found to recognize HREs within the promoters of a large number of genes following hypoxic induction. The list of confirmed HIF target genes (e.g., see Wenger 2002) is ever expanding and can be grouped into a number of subclasses. Many of these target genes promote cellular adaptation to reduced oxygen availability through an increase in glucose uptake and glycolysis (GLUT1, lactate dehydrogenase A). Other HIF target genes increase oxygen transport to hypoxic tissues by promoting red blood cell maturation (e.g., Epo, transferrin) or angiogenesis/ vasomotor control (including VEGF, endothelin-1). Although several HIF target genes promote cell proliferation and survival (insulin-like growth factor [IGF] 2 and IGF-binding proteins 1, 2, and 3), failure to adapt to lowoxygen conditions will eventually lead to cell death via apoptosis. HIF-1 has been shown to play a role in promoting apoptosis under conditions of chronic hypoxia (Carmeliet et al. 1998), and the gene encoding the prodeath factor Nip3 is induced in response to hypoxia via an HRE located within its promoter (Bruick 2000). Nip3 has subsequently been shown to be overexpressed in perinecrotic regions of human tumors (Sowter et al. 2001). This HIF-dependent hypoxic response may provide a strong selective pressure for the accumulation of secondary mutations in tumor suppressor genes (Graeber et al. 1996). Taking these findings together, it comes as no surprise that the HIF-dependent hypoxic response pathway plays a prominent role in mediating the consequences of many disease states, including cerebral and myocardial ischemia, pulmonary hypertension, and tumorigenesis (Semenza 2000).

HIF is a heterodimeric transcription factor composed of an HIF- $\alpha$ subunit and an HIF- $\beta$ subunit also known as the aryl hydrocarbon receptor nuclear translocator (ARNT; Wang et al. 1995b). Both HIF subunits are members of the basic helix-loop-helix (bHLH)-containing PER-ARNT-SIM (PAS) domain family of transcription factors. Each subunit contains two PAS domains, designated PAS-A and PAS-B. PAS domains typically encompass 100-120 amino acids, folding into a five-stranded antiparallel $\beta$-sheet flanked by several $\alpha$-helices. As shown in Figure 1, the PAS domains are thought to mediate heterodimer formation between the $\alpha$ - and $\beta$-sub- 


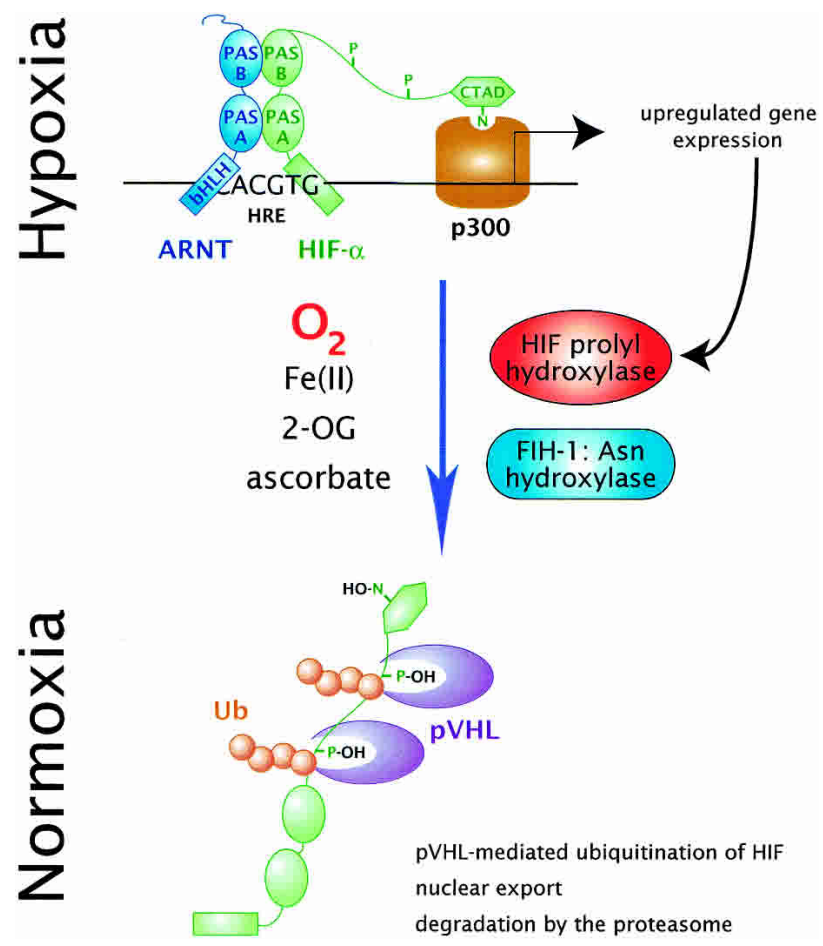

Figure 1. Hypoxia-mediated regulation of HIF stabilization and activation. Under normoxic conditions (bottom), two proline residues within the ODD of the HIF- $\alpha$ subunit are modified by the EGLN/HPH/PHD family of HIF-prolyl hydroxylases, allowing for HIF-recognition by a protein-ubiquitin ligase complex containing $\mathrm{pVHL}$, and leading to HIF- $\alpha$ degradation by the proteasome. Meanwhile, the asparaginyl hydroxylase FIH-1 modifies the CTAD of the HIF- $\alpha$, blocking its interaction with transcriptional coactivators such as p300. When oxygen levels decrease (Hypoxia), both prolyl and asparaginyl hydroxylation are blocked. HIF- $\alpha$ accumulates and interacts with the HIF- $\beta$ subunit (ARNT) and the larger transcriptional machinery, thereby promoting transcription of downstream HIF target genes that include the HIF prolyl hydroxylase, among others.

units and to be necessary for DNA binding (Jiang et al. 1996a). The PAS domains may also influence HIF activity through associations with hsp90 (Minet et al. 1999; Isaacs et al. 2002) and mediate target gene specificity via interactions with currently unidentified factors (Zelzer et al. 1997). PAS domains are exceptional protein-protein interaction domains in that they frequently exhibit environmental sensing capability, either through direct ligand binding or by integrating cofactors within their hydrophobic cores (for review, see Taylor and Zhulin 1999). To date, no environmental sensing or ligand/cofactor binding activity has been reported for the HIF PAS domains.

In mammals, three genes have been shown to encode HIF- $\alpha$ subunits that appear to be regulated in a similar manner (Wiesener et al. 1998; O'Rourke et al. 1999; Srinivas et al. 1999) with a few exceptions (Makino et al. 2002; Park et al. 2003). The HIF-1 $\alpha$ protein is ubiquitously expressed (Wiener et al. 1996; Jain et al. 1998), whereas its homologs, HIF-2 $\alpha /$ Endothelial PAS domain protein (EPAS; Tian et al. 1997; Wiesener et al. 2003) and HIF-3 $\alpha$ (Gu et al. 1998), have more restricted expression patterns. HIF- $\beta$ is generally found to be constitutively expressed and insensitive to changes in oxygen availability, whereas the $\alpha$-subunit is acutely regulated in response to hypoxia (Jiang et al. 1996b). Although there is evidence for hypoxic induction of HIF- $\alpha$ mRNA levels in some cell types (Wang et al. 1995a; Heidbreder et al. 2003 ), the predominant modes of HIF- $\alpha$ regulation occur posttranslationally.

In most experimental systems, the HIF- $\alpha$ protein subunits are constitutively expressed but rapidly degraded when sufficient oxygen is present (normoxia). Following a shift to a low-oxygen environment, the $\alpha$-subunit is stabilized and subsequently translocated into the nucleus (Fig. 1). Regulation of the $\alpha$-subunit stability is mediated through a region referred to as the oxygen-dependent degradation domain (ODD; Huang et al. 1998). Under normoxic conditions, the ODD is recognized by the product of the von Hippel-Lindau (pVHL) tumor suppressor gene, a component of a multisubunit ubiquitinprotein ligase complex (Maxwell et al. 1999; Cockman et al. 2000; Kamura et al. 2000; Ohh et al. 2000; Tanimoto et al. 2000) that tags the subunit with polyubiquitin to promote HIF- $\alpha$ degradation by the proteasome (Fig. 1; Salceda and Caro 1997; Huang et al. 1998; Kallio et al. 1999). pVHL fails to recognize the HIF- $\alpha$ subunit when cells are exposed to a hypoxic environment (Ivan et al. 2001; Jaakkola et al. 2001), allowing HIF to accumulate. Once in the nucleus, HIF $\alpha$-dimerizes with the $\beta$-subunit ARNT and binds to HREs within the promoters of its target genes.

The HIF- $\alpha$ subunit contains two transcriptional activation domains bridged by an inhibitory domain (Jiang et al. 1997; Pugh et al. 1997). Exposure to a hypoxic environment relieves suppression of the activation domains, leading to increased transcription of target genes. The $\mathrm{N}$-terminal transactivation domain (NTAD) overlaps with the ODD, and its regulation is difficult to separate from that of protein stability. However, the ability of the $\mathrm{C}$-terminal transactivation domain (CTAD) to interact with coactivators such as $\mathrm{CBP} / \mathrm{p} 300$ is induced by hypoxia (Ema et al. 1999; Carrero et al. 2000; Kung et al. 2000; Gu et al. 2001), independent of protein stability, and is required for full HIF activity (Lando et al. 2002b).

\section{Fe(II)-dependent dioxygenase enzymes mediate HIF stability}

The mechanism by which changes in oxygen availability affect changes in HIF stability and activity remained elusive for many years. Early circumstantial evidence suggested that a global heme-based sensor might detect $\mathrm{O}_{2}$ levels (Goldberg et al. 1988). Later models emphasized the role of signaling pathways that mediate HIF regulation through changes in the phosphorylation and/or redox state of HIF- $\alpha$ (Salceda and Caro 1997; Chandel et al. 2000). An important breakthrough came with the discovery that pVHL recognition of the HIF- $1 \alpha$ subunit was dependent upon hydroxylation of conserved proline resi- 
dues within the ODD under normoxic conditions (Ivan et al. 2001; Jaakkola et al. 2001; Yu et al. 2001). As later demonstrated in the crystal structures of the pVHL-ElonginB-ElonginC complex bound to a hydroxylated HIF-derived peptide, the hydroxyproline residue becomes buried within the hydrophobic core of $\mathrm{pVHL}$, making hydrogen bonds with specific histidine and serine residues which provide the basis for discrimination via modification (Hon et al. 2002; Min et al. 2002). Hydroxylation, and subsequent pVHL-mediated ubiqitination of HIF- $\alpha$, does not take place under hypoxic conditions, resulting in HIF accumulation.

These data implied the existence of a prolyl hydroxylase enzyme in the hypoxic response pathway. This hypothesis was supported by the finding that HIF modification was dependent on both $\mathrm{Fe}(\mathrm{II})$ and 2-oxoglutarate (Ivan et al. 2001; Jaakkola et al. 2001; Yu et al. 2001), reminiscent of well characterized hydroxylase enzymes that modify collagen in the endoplasmic reticulum (Kivirikko and Pihlajaniemi 1998). A family of three HIF prolyl hydroxylases has since been identified using candidate approaches (Bruick and McKnight 2001; Epstein et al. 2001) and a subsequent unbiased biochemical purification of hydroxylase activity (Ivan et al. 2002). Inactivation of these enzymes in Drosophila melanogaster (Bruick and McKnight 2001; Lavista-LLanos et al. 2002) and Caenorhabditis elegans (Epstein et al. 2001) promotes HIF stability and activity, verifying their role in the pathway. An additional candidate prolyl hydroxylase enzyme has also been proposed to regulate HIF, although experimental support for such a role is limited (Oehme et al. 2002). Like other known prolyl hydroxylases, the relevant HIF prolyl hydroxylases utilize molecular oxygen as a substrate to catalyze hydroxylation of the target proline residues (Fig. 2A). Because $\mathrm{O}_{2}$ availability appeared to be rate-limiting for prolyl hydroxylase activity (Epstein et al. 2001), these enzymes were purported to act as bona fide oxygen sensors that provide a direct link between $\mathrm{O}_{2}$ concentration and components of the hypoxic response pathway.

\section{Physiological roles of the HIF prolyl hydroxylases}

All three paralogs of the HIF prolyl hydroxylase family have been shown to modify the HIF $\alpha$-subunits in vitro (Bruick and McKnight 2001; Epstein et al. 2001). The proteins encoded by these genes share a highly conserved C-terminal region responsible for hydroxylase activity but differ greatly at the $\mathrm{N}$ terminus. The three hydroxylase genes are expressed in many of the same tissues, although differences do exist in their expression patterns and their induction in response to various growth factors and developmental cues (Lieb et al. 2002; Cioffi et al. 2003). The necessity for three enzymes and the difference among their in vivo roles remain unclear, although clues are beginning to emerge.

The HIF- $\alpha$ polypeptides contain two sites for hydroxylation, Pro 402 and Pro 564. Each site contains a conserved LXXLAP motif that can independently be recognized by pVHL following modification to promote rapid
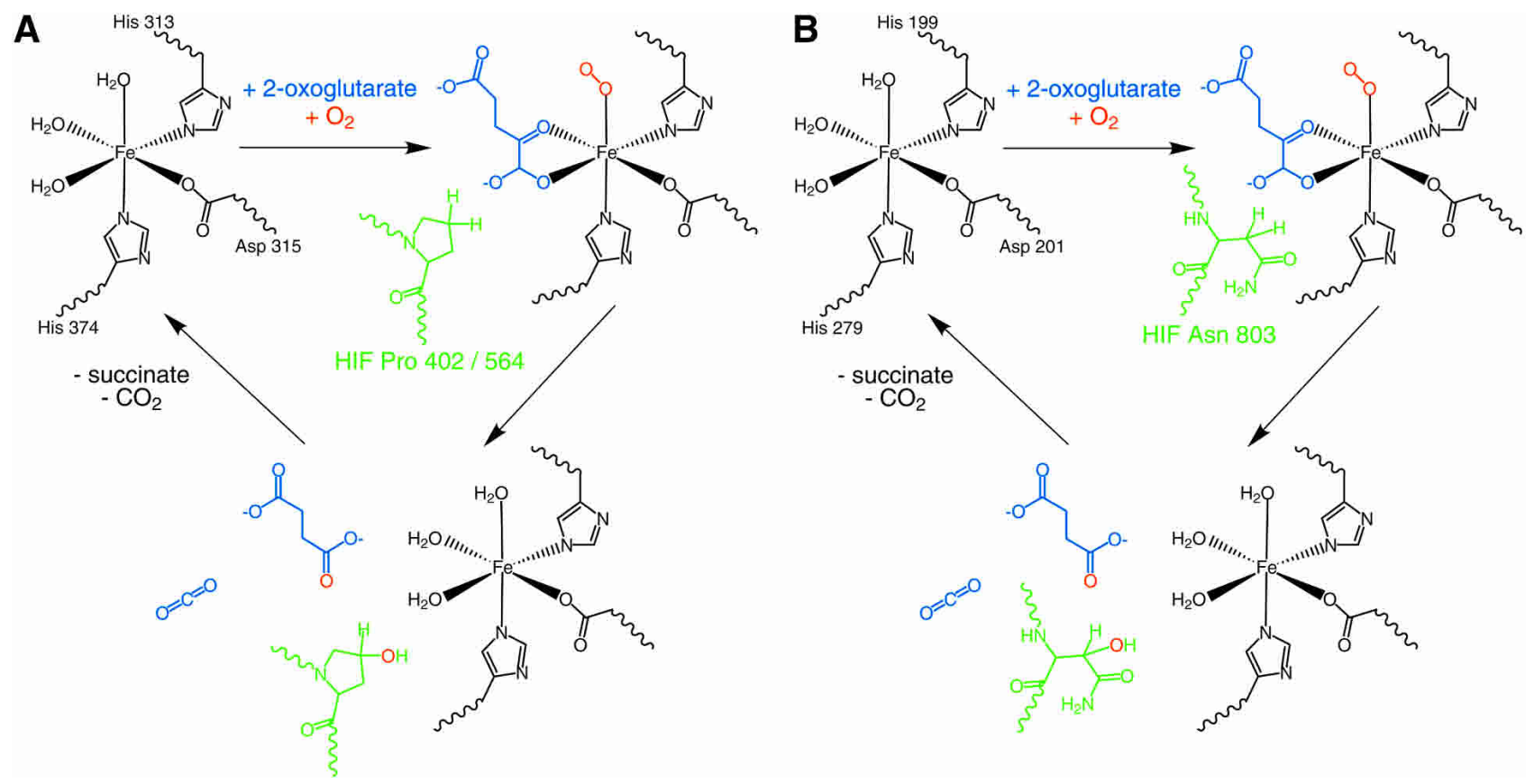

Figure 2. Modification of the HIF- $\alpha$ polypeptide by the HIF prolyl and asparaginyl hydroxylases. EGLN/HPH/PHD hydroxylates HIF- $1 \alpha$ at Pro 402 and Pro $564(A)$ while FIH-1 hydroxylates Asn $803(B)$. The active sites contain Fe(II) coordinated by a His-XAsp . . . His triad. The enzymes bind 2-oxoglutarate (2-OG), the HIF polypeptide substrate, and $\mathrm{O}_{2}$ to affect hydroxylation of both HIF- $\alpha$ and 2-oxoglutarate. In the course of the reaction, molecular oxygen is consumed and hydroxylated 2-oxoglutarate undergoes decarboxylation to give succinate and carbon dioxide. The residue numbers correspond to human HIF-1 $\alpha$, the EGLN1/HPH-2/PHD2 prolyl hydroxylase, and the FIH-1 asparaginyl hydroxylase. 
HIF degradation, although subtle differences in the requirements for $\mathrm{pVHL}$ recognition were observed (Masson et al. 2001). The hydroxylases show distinct preferences for each ODD substrate, with the Pro 564 site hydroxylated by all three enzymes, whereas Pro 402 is only effectively modified by two of the isoforms (Epstein et al. 2001; Hirsila et al. 2003).

Differences between the enzymes can also be seen in their patterns of intracellular localization when overexpressed as tagged proteins (Huang et al. 2002; Metzen et al. 2003). GPF fusions to EGLN1/HPH-2/PHD2 reside in the cytoplasm, whereas EGLN2/HPH-3/PHD1 is predominantly nuclear. EGLN3/HPH-1/PHD3 fusions were distributed evenly between both compartments (Metzen et al. 2003). This is in contrast to early studies of the rat EGLN3/HPH-1/PHD3 protein, which localized in the mitochondria (Lipscomb et al. 2001). However, the Nterminal mitochondrial targeting sequence of the rat protein does not appear to be conserved among other mammals such as humans (Taylor 2001).

Although these differences in expression patterns, cellular distribution, and substrate selectivity imply distinct functions for the three enzymes, the physiological consequences of these differences are less clear. To address this question, a recent study employed an RNA interference (RNAi) strategy to individually suppress expression of the three HIF prolyl hydroxylase paralogs in a variety of human cell lines (Berra et al. 2003). RNAimediated silencing of two of the hydroxylase genes did not promote HIF accumulation under normoxic conditions; nor did the loss of either gene product preclude HIF degradation upon reoxygenation following hypoxic induction (Berra et al. 2003). Inhibition of EGLN1/HPH$2 / \mathrm{PHD} 2$, the ancestral form of the gene family (Taylor 2001), did result in HIF accumulation under normoxic conditions and a reduced rate of HIF turnover following reoxygenation (Berra et al. 2003). Together these data indicate that the EGLN1/HPH-2/PHD2 enzyme is primarily responsible for determining HIF- $\alpha$ stability as a function of oxygen availability. This finding raises some interesting questions. How does $\mathrm{HPH}-2$ promote degradation of HIF upon reoxygenation if $\mathrm{HPH}-2$ is primarily localized to the cytoplasm while HIF is functioning in the nucleus? Secondly, what are the physiological roles of the other hydroxylase isoforms, all of which are capable of modifying HIF in vitro? One hint uncovered in the RNAi studies points to a role for EGLN2/HPH-3/ PHD1 in mediating HIF stability following long-term EGLN1/HPH-2/PHD2 depletion (Berra et al. 2003).

\section{A Fe(II)-dependent dioxygenase enzyme mediates HIF activity}

The ability of the HIF- $\alpha$ CTAD to interact with coactivators such as CBP/p300 only under hypoxic conditions is also regulated by a hydroxylation-dependent switch (Lando et al. 2002b; Sang et al. 2002). By itself, the HIF- $\alpha$ CTAD is largely unstructured in solution but can adopt an extended helical structure when bound to CBP/p300 (Dames et al. 2002; Freedman et al. 2002). Under nor- moxic conditions, this interaction is blocked by hydroxylation of the $\beta$-carbon (McNeill et al. 2002) of a conserved asparagine residue within the CTAD (Lando et al. 2002b). Hydroxylation of this asparagine residue, ordinarily buried deep within the CBP/p300-HIF hydrophobic interface, creates unfavorable interactions that interfere with binding (Dames et al. 2002; Freedman et al. 2002). As was seen with prolyl hydroxylation, the modification of the asparagine residue is abrogated by hypoxia, allowing the CTAD to interact with $\mathrm{CBP} / \mathrm{p} 300$. The effect of this modification on interactions between the CTAD and other associated factors, including SRC-1 and REF-1 (Carrero et al. 2000), has not been determined.

Factor inhibiting HIF-1 (FIH-1; Mahon et al. 2001), a CTAD-interacting protein later shown to possess asparaginyl hydroxylase activity (Hewitson et al. 2002; Lando et al. 2002a), carries out this regulation. Like the prolyl hydroxylases (Fig. 2B), FIH-1 is a Fe(II)- and 2-oxoglutarate-dependent dioxygenase enzyme (Hewitson et al. 2002; Lando et al. 2002a). FIH-1 is predominantly found in the cytoplasm, with some protein likely residing in the nucleus as well (Metzen et al. 2003). Structural analysis has revealed that FIH-1 is a functional homodimer with self-association mediated through its $\mathrm{C}$ terminus (Dann et al. 2002; Elkins et al. 2003; Lee et al. 2003). FIH-1 recognition of the HIF CTAD substrate is determined by multiple interaction sites (Elkins et al. 2003).

As with the prolyl hydroxylases, utilization of oxygen as a substrate provides FIH-1 with the potential to serve as a second cellular oxygen sensor within the hypoxic response pathway. Although FIH-1 has been reported to be sensitive to oxygen concentrations in the relevant hypoxic range (Hewitson et al. 2002), overexpression of FIH-1 can still prevent hypoxic induction of CTAD (Mahon et al. 2001; Lando et al. 2002a), in contrast to the prolyl hydroxylases (Bruick and McKnight 2001). It may be that FIH-1 can also affect CTAD suppression through reported association with pVHL and histone deacetylase complexes (Mahon et al. 2001) independent of its hydroxylase activity. Although HIF expression and activity may be fine-tuned by additional mechanisms (for review, see Wenger 2002), the $\mathrm{O}_{2}$-dependent hydroxylases appear to be primarily responsible for regulating the rapid induction of HIF in response to hypoxia and show promise as targets for therapeutic intervention.

\section{Are HIF prolyl hydroxylases $\mathrm{O}_{2}$-sensors?}

Two facets of HIF regulation have been shown unequivocally to depend on oxygen availability-HIF- $\alpha$ stability and coactivator recruitment by the CTAD. With the discovery that these modes of regulation were largely dependent on the prolyl and asparaginyl hydroxylases came the prediction that these enzymes would be actual oxygen sensors by virtue of their affinity for oxygen. While providing an elegant solution to the oxygen-sensing problem, this hypothesis remained to be demonstrated directly. For instance, the $\mathrm{K}_{\mathrm{m}}$ for $\mathrm{O}_{2}$ for the collagenmodifying hydroxylases (Hirsila et al. 2003) is fairly low 
(40 $\mu \mathrm{M})$, allowing for significant hydroxylase activity even under concentrations of oxygen that induce an HIFdependent response. It has been suggested that the dependence of $\mathrm{O}_{2}$ as a substrate for the enzymes serves only as a crude switch-inactivated under anoxic conditions but incapable of providing a graded HIF response under hypoxia (Schumacker 2002). The affinities of the three recombinant prolyl hydroxylases for oxygen were recently reported to be in the $230-250 \mu \mathrm{M}$ range (Hirsila et al. 2003). These values are near the concentration of oxygen in the atmosphere and well above the oxygen concentration reported for most "normoxic" tissues which normally operate under near-hypoxic conditions (Stroka et al. 2001). If the $\mathrm{K}_{\mathrm{m}}\left[\mathrm{O}_{2}\right]$ values for recombinant enzymes accurately reflect the $\mathrm{K}_{\mathrm{m}}\left[\mathrm{O}_{2}\right]$ values of endogenous hydroxylases in vivo, then these enzymes are acting under nonequilibrium conditions and should be affected by small changes in oxygen availability-fulfilling a role as an $\mathrm{O}_{2}$-sensor.

Although oxygen availability directly affects hydroxylase activity by virtue of it being a substrate for the enzymes, oxygen also appears to fine-tune hydroxylationmediated HIF stability via a negative feedback mechanism. In response to hypoxia and hypoxia "mimics", mRNA levels of two of the mammalian hydroxylase paralogs accumulate (Table 1; Epstein et al. 2001; Cioffi et al. 2003; Metzen et al. 2003). A similar observation has likewise been reported for the single fly and worm homologs (Epstein et al. 2001; Lavista-LLanos et al. 2002). Transcript accumulation is accompanied by an increase in both protein and activity levels (Epstein et al. 2001; Berra et al. 2003; D'Angelo et al. 2003; Metzen et al. 2003). Hypoxic induction of hydroxylase activity may partially suppress hypoxic induction of HIF and likely promotes much more rapid degradation of the $\alpha$-subunit upon reoxygenation (Berra et al. 2001, 2003). The absolute contribution of this feedback mechanism to the regulation of HIF stability as a function of physiological hypoxia is difficult to quantitate and likely depends on the severity and duration of the hypoxic stress. Hypoxic induction of the prolyl hydroxylase mRNAs appears to be dependent on the HIF transcription factor itself (Lavista-LLanos et al. 2002; Berra et al. 2003), although HREs within the promoter elements of the genes have not yet been reported.

Translocation of the HIF $\alpha$-subunit from the cytoplasm to the nucleus has also been examined as a func- tion of oxygen availability. Early studies produced mixed results, with some studies reporting nuclear accumulation of HIF under hypoxia (Kallio et al. 1998; LavistaLLanos et al. 2002) whereas others found that overexpressed HIF- $\alpha$ protein constitutively enters the nucleus under normoxic conditions (Hofer et al. 2001). For the Drosophila homolog of HIF, deletion of the ODD or pVHL removes hypoxic control of cellular localization, suggesting a possible relationship between hydroxylasemediated stability and localization (Lavista-LLanos et al. 2002). In reoxygenated cells, hydroxylated HIF- $\alpha$ is recognized by pVHL and is transported back to the cytoplasm by a constitutive nuclear-cytoplasmic pVHL shuttle (Groulx and Lee 2002). In the model derived from these data, HIF- $\alpha$ translocation to the nucleus is indeed oxygen-independent; however, retention of HIF- $\alpha$ in the nucleus requires hypoxic down-regulation of the hydroxylase-dependent $\mathrm{pVHL}$ recognition.

Although there is no question that the prolyl and asparaginyl hydroxylases are key components of the physiological oxygen-sensing pathway in cells, HIF is also regulated by additional $\mathrm{O}_{2}$-independent (Bilton and Booker 2003) and $\mathrm{O}_{2}$-dependent events. A new posttranslational modification of HIF- $\alpha$ was recently reported, acetylation of a lysine residue (Lys 532) in close proximity to Pro 564 by the acetyltransferase ARD1 (Jeong et al. 2002). Those authors proposed that acetylation of this residue works in conjunction with the nearby hydroxylated proline residue to facilitate $\mathrm{pVHL}$ recognition of HIF under normoxic conditions (Jeong et al. 2002). Interestingly, acetylation of the HIF $\alpha$-subunit also appears to occur preferentially under normoxic conditions (Jeong et al. 2002). The mechanism for ARD1 regulation as a function of oxygen availability is less obvious than that of the hydroxylase enzymes. ARD1 mRNA levels do decrease following several hours of hypoxic exposure (Jeong et al. 2002), but it is unclear whether this accounts for the observed decrease in acetylated HIF. Furthermore, ARD1 was found exclusively in the cytosol (Jeong et al. 2002), suggesting that ARD1-dependent acetylation of HIF- $\alpha$ is not required for $\mathrm{pVHL}$ recognition in the nucleus upon reoxygenation.

\section{Oxygen-independent regulation of the hydroxylases}

The HIF regulatory hydroxylases mediate the HIF response to hypoxia and are, in turn, themselves affected.

Table 1. Properties of the HIF prolyl hydroxylases

\begin{tabular}{lcccccc}
\hline & \multicolumn{2}{c}{ Substrate } & & & & \\
\cline { 2 - 5 } Gene & p402 & P564 & Localization & RNAi & Hyp. induce & Tissue distribution \\
\hline EGLN1/HPH-2/PHD2 & + & + & C $>$ N & +++ & + & liver $=$ heart $>$ brain $=$ kidney $>$ lung \\
EGLN2/HPH-3/PHD1 & + & + & N & + & - & testis $>$ liver $>$ kidney $=$ heart $=$ brain \\
EGLN3/HPH-1/PHD3 & - & + & C/N & - & + & heart $>$ liver $>$ brain $>$ kidney $>$ lung \\
\hline
\end{tabular}

Summary of the physiological properties of the three HIF prolyl hydroxylases indicating their ability to modify Pro402/564, intracellular localization (N, nuclear; $\mathrm{C}$, cytosolic), ability to mediate HIF stability as determined by RNA interference, induction of hydroxylase mRNA expression in response to hypoxia, and tissue expression patterns.

${ }^{\text {a }}$ Rat protein targeted to the mitochondria. 
Besides oxygen, what else might contribute to the regulation of these prolyl and asparaginyl hydroxylases? The HIF prolyl hydroxylases have been reported to be regulated at the level of enzyme expression in response to growth factors (Moschella et al. 1999; Lipscomb et al. 2001; Erez et al. 2002). The relevance of these findings to the regulation of HIF activity remains unclear. It is possible that these enzymes affect additional cellular responses in addition to their role in the hypoxic response pathway. Consistent with this hypothesis, the C. elegans homolog of the HIF prolyl hydroxylase genes, egl9 , has been identified in genetic screens for egg-laying deficiencies (Trent et al. 1983) and pathogen resistance (Darby et al. 1999). Thus far, no additional substrates have been identified for the HIF hydroxylases. Although substrate sequence preferences do exist, mutations can be tolerated in all of the residues residing in the vicinity of the target prolines of the HIF substrates (Huang et al. 2002). Consequently, there are likely to be many other potential substrates for these enzymes in the absence of additional targeting constraints. It was recently demonstrated that the large subunit of RNA polymerase II is targeted for degradation upon binding by $\mathrm{pVHL}$ following hydroxylation of a proline residue (Kuznetsova et al. 2003). Although the relevant hydroxylase enzyme has not been identified, the modification site shares the LXXLAP site found in HIF (Kuznetsova et al. 2003).

As shown in Figure 2, these hydroxylases modify both 2-oxoglutarate as well as the HIF- $\alpha$ polypeptide to produce the hydroxylated substrates in addition to $\mathrm{CO}_{2}$ and succinate. Furthermore, these enzymes require the presence of $\mathrm{Fe}(\mathrm{II})$ at the reaction center and depend on the presence of ascorbate for full activity, presumably to maintain iron in the $\mathrm{Fe}(\mathrm{II})$ state. Changes in the cellular levels of any of these substrates, products, or cofactors could potentially influence hydroxylase activity and its downstream effects on the HIF pathway. To this end, supplementation of cells with ascorbate has been shown to promote HIF degradation through increased hydroxylase activity (Knowles et al. 2003). Because physiological levels of ascorbate (25-50 $\mu M_{;}$Knowles et al. 2003) are well below the $\mathrm{K}_{\mathrm{m}}$ values of the prolyl hydroxylases for ascorbate (140-170 $\mu \mathrm{M}_{;}$Hirsila et al. 2003), it is easy to imagine that changes in ascorbate levels could significantly influence enzymatic activity. The addition of iron to cells in culture had a similar effect on stimulating HIF turnover (Knowles et al. 2003), and it has long been known that iron chelators or competing metal ions promote HIF stabilization. Whether the bioavailability of these cofactors affects hydroxylase activity in vivo remains to be determined. Interestingly, many downstream target genes for the HIF transcription factor are involved in iron metabolism and may themselves contribute to an additional mode of feedback regulation. The same holds true for levels of 2-oxoglutarate and succinate, both products of the tricarboxylic acid cycle that should have opposing effects on hydroxylase activity. It has been proposed that HIF is affected in a prolyl hydroxylase-dependent fashion by signals generated from the mitochondria. Although some data suggest that these signals are composed of reactive oxygen species (Schroedl et al. 2002), it may be that the enzymes are compromised by these metabolism intermediates.

Lastly, the HIF transcription factor not only accumulates in response to hypoxia but also in response to activation of a number of cellular signaling pathways. It is thought that many of these signaling pathways act to promote HIF- $\alpha$ translation under normoxic conditions (for review, see Semenza 2002). It was recently suggested that the action of the RasV12 and v-Src pathways may be mediated in part through inhibition of HIF prolyl hydroxylation (Chan et al. 2002). Although the hydroxylases themselves have not yet been shown to be a target for posttranslational modification, they remain potential targets for rapid regulation by upstream signaling pathways.

\section{$\mathrm{Fe}(\mathrm{II})$-dependent dioxygenase enzymes as targets for therapeutic intervention}

The HIF transcription factor has now been shown to play a role in the progression of a number of disease states. Because HIF can mediate the coordinate expression of a number of genes, it may provide a superior pharmacological target to promote adaptation to hypoxic stress encountered by patients suffering from myocardial or cerebral ischemia. For example, constitutive normoxic expression of a stabilized HIF- $1 \alpha$ gene lacking the ODD in the keratinocytes of mice led to an increase in peripheral vascularization that was not accompanied by inflammation and vessel leakage observed in mice overexpressing a single HIF target gene, VEGF (Elson et al. 2001). Inhibition of the relevant hydroxylase activity under normoxic conditions would be predicted to have a similar effect-induction of multiple genes promoting angiogenesis, erythropoieses, glycolysis, vasomotor control, and cellular viability. Such an approach was validated in tissue culture systems through the introduction of ODDderived peptides that compete with HIF for prolyl hydroxylase recognition. The resultant stabilization of HIF led to an induction of downstream target genes such as VEGF and GLUT-1 and a subsequent pro-angiogenic response (Willam et al. 2002).

From a practical standpoint, it would be desirable to identify small-molecule inhibitors of the relevant prolyl and asparaginyl hydroxylases. Fortunately, years of research on inhibitors of the collagen-modifying enzymes have provided investigators with a large number of hydroxylase inhibitors to investigate. Several groups have now identified both natural products (Mabjeesh et al. 2003; Schlemminger et al. 2003; Warnecke et al. 2003) and small-molecule compounds (Ivan et al. 2002; Hirsila et al. 2003; Wright et al. 2003) capable of inhibiting the regulatory hydroxylases and inducing HIF-dependent responses. These compounds typically fall into two classes, iron chelators and competitive inhibitors of 2-oxoglutarate. Although these classes of compounds might be expected to inhibit all hydroxylases, early results have indicated that there are differential specificities for individual inhibitors among the various enzymes 
(Ivan et al. 2002; Hirsila et al. 2003). Comparison of the active sites of multiple hydroxylases shows that 2-oxoglutarate contacts distinct residues in the different proteins, providing a basis for selectivity among the analogs (Dann et al. 2002; Elkins et al. 2003). With the likelihood that the numbers of $\mathrm{Fe}(\mathrm{II})$ - and 2-oxoglutarate-dependent hydroxylases identified in other biological pathways will expand (Aravind and Koonin 2001), the need for highly selective hydroxylase inhibitors becomes increasingly important.

Despite the warranted enthusiasm for hydroxylase inhibition as a therapeutic strategy, there may be unintended deleterious consequences to prolonged HIF induction resulting from chronic hydroxylase inhibition. Of particular concern is the potential for HIF to cause the formation of new tumors, given HIF's well characterized contribution to tumor progression. Fortunately there has thus far been no indication that constitutive overexpression of HIF alone is sufficient to cause new tumor formation (e.g., see Elson et al. 2001). Nevertheless, investigators will no doubt be on the lookout for such complications as these compounds progress through drug development programs. It is worth noting that many potential therapeutic applications of such inhibitors need not require long-term administration.

\section{Conclusions and future directions}

Despite the substantial gains made in our understanding of $\mathrm{O}_{2}$-dependent regulation of the hypoxic response pathway, many important questions remain unanswered. Clearly the prolyl and asparaginyl hydroxylases are key contributors to the regulation of the HIF transcription factor and can independently mediate HIF function simply by their utilization of oxygen, but does this property fully account for hypoxic induction of the HIF response pathway? It will be of great interest to determine the contributions of $\mathrm{Fe}(\mathrm{II})$, 2-oxoglutarate, and ascorbate availability to the regulation of hydroxylase activity. Furthermore, new mechanisms for hydroxylase regulation are likely to be uncovered as regulation of these enzymes as a function of upstream signaling pathways is studied in greater detail. It is also possible that the various HIF regulatory components do not operate completely independently of one another. For instance, cross-talk may exist between the machinery responsible for maintaining HIF stability and CTAD activity, as $\mathrm{pVHL}$ has been reported to interact with both pVHL and histone deacetylase complexes (Mahon et al. 2001). The prolyl hydroxylases have large $\mathrm{N}$-terminal domains that are not required for hydroxylase activity and may mediate additional hydroxylase functions. Might these enzymes also function as part of a larger complex? The need for multiple prolyl hydroxylases is likewise of interest and merits additional investigation. Do the various proteins carry out specific roles solely as a function of their spatial and/or temporal expression pattern or do they perform nonoverlapping roles that extend beyond their role in HIF regulation? Although RNAi studies have begun to address these questions (Berra et al. 2003), mouse knockout models of the individual hydroxylase genes should provide a wealth of information in the future. As the list of HIF regulatory factors grows, so too does our appreciation for the exquisite control nature has provided for this pathway. The multiple layers of regulation are a reminder that HIF plays a role under both normoxic and hypoxic conditions that must be tightly and dynamically governed. This network of regulation is a necessity when considering the physiological range of oxygen concentrations encountered in both healthy and compromised tissues. Given the key role HIF plays both in embryonic development and the pathogenesis of cancer, stroke, and heart disease, our increased understanding of HIF regulation promises to provide new avenues for potential therapeutic intervention.

\section{Acknowledgments}

R.K.B. is the Michael L. Rosenberg Scholar in Medical Research and is supported by a Burroughs Wellcome Fund Career Award in the Biomedical Sciences.

\section{References}

Aravind, L. and Koonin, E.V. 2001. The DNA-repair protein AlkB, EGL-9, and leprecan define new families of 2-oxoglutarate- and iron-dependent dioxygenases. Genome Biol. 2: $1-8$.

Berra, E., Richard, D.E., Gothie, E., and Pouyssegur, J. 2001. HIF-1-dependent transcriptional activity is required for oxygen-mediated HIF-1 $\alpha$ degradation. FEBS Lett. 491: 85-90.

Berra, E., Benizri, E., Ginouvès, A., Volmat, V., Roux, D., and Pouysségur, J. 2003. HIF prolyl-hydroxylase 2 is the key oxygen sensor setting low steady-state levels of HIF- $1 \alpha$ in normoxia. EMBO I. 22: 4082-4090.

Bilton, R.L. and Booker, G.W. 2003. The subtle side to hypoxia inducible factor $(\mathrm{HIF} \alpha)$ regulation. Eur. J. Biochem. 270: 791798.

Bruick, R.K. 2000. Expression of the gene encoding the proapoptotic Nip3 protein is induced by hypoxia. Proc. Nat1. Acad. Sci. 97: 9082-9087.

Bruick, R.K. and McKnight, S.L. 2001. A conserved family of prolyl-4-hydroxylases that modify HIF. Science 294: 1337 1340.

Carmeliet, P., Dor, Y., Herbert, J.M., Fukumura, D., Brusselmans, K., Dewerchin, M., Neeman, M., Bono, F., Abramovitch, R., Maxwell, P., et al. 1998. Role of HIF-1 $\alpha$ in hypoxiamediated apoptosis, cell proliferation and tumour angiogenesis. Nature 394: 485-490.

Carrero, P., Okamato, K., Coumailleau, P., O’Brien, S., Tanaka, H., and Poellinger, L. 2000. Redox-regulated recruitment of the transcriptional coactivators CREB-binding protein and SRC-1 to hypoxia-inducible factor $1 \alpha$. Mol. Cell. Biol. 20: $402-415$.

Chan, D.A., Sutphin, P.D., Denko, N.C., and Giaccia, A.J. 2002. Role of prolyl hydroxylation in oncogenically stabilized hypoxia-inducible factor-1 $\alpha$. J. Biol. Chem. 277: 40112-40117.

Chandel, N.S., McClintock, D.S., Feliciano, C.E., Wood, T.M., Melendez, J.A., Rodriguez, A.M., and Schumacker, P.T. 2000. Reactive oxygen species generated at mitochondrial Complex III stabilize hypoxia-inducible factor $1 \alpha$ during hypoxia. J. Biol. Chem. 275: 25130-25138.

Cioffi, C.L., Liu, X.Q., Kosinski, P.A., Garay, M., and Bowen, 
B.R. 2003. Differential regulation of HIF-1 $\alpha$ prolyl-4-hydroxylase genes by hypoxia in human cardiovascular cells. Biochem. Biophys. Res. Commun. 303: 947-953.

Cockman, M.E., Masson, N., Mole, D.R., Jaakkola, P., Chang, G.W., Clifford, S.C., Maher, E.R., Pugh, C.W., Ratcliffe, P.J., and Maxwell, P.H. 2000. Hypoxia inducible factor- $\alpha$ binding and ubiquitylation by the von Hippel-Lindau tumor suppressor protein. J. Biol. Chem. 275: 25733-25741.

D'Angelo, G., Duplan, E., Boyer, N., Vigne, P., and Frelin, C. 2003. Hypoxia up regulates prolyl hydroxylase. A feedback mechanism that limits HIF-1 responses during reoxygenation. J. Biol. Chem 278: 38183-38187.

Dames, S.A., Martinez-Yamout, M., De Guzman, R.N., Dyson, H.J., and Wright, P.E. 2002. Structural basis for Hif- $1 \alpha /$ CBP recognition in the cellular hypoxic response. Proc. Natl. Acad. Sci. 99: 5271-5276.

Dann III, C.E., Bruick, R.K., and Deisenhofer, J. 2002. Structure of FIH-1: An asparaginyl hydroxylase involved in the hypoxic response pathway. Proc. Natl. Acad. Sci. 99: 1535115356.

Darby, C., Cosma, C.L., Thomas, J.H., and Manoil, C. 1999. Lethal paralysis of Caenorhabditis elegans by Pseudomonas aeruginosa. Proc. Nat1. Acad. Sci. 96: 15202-15207.

Elkins, J.M., Hewitson, K.S., McNeill, L.A., Seibel, J.F., Schlemminger, I., Pugh, C.W., Ratcliffe, P.J., and Schofield, C.J. 2003. Structure of factor-inhibiting hypoxia-inducible factor (HIF) reveals mechanism of oxidative modification of HIF-1

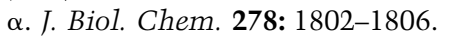

Elson, D.A., Thurston, G., Huang, L.E., Ginzinger, D.G., McDonald, D.M., Johnson, R.S., and Arbeit, J.M. 2001. Induction of hypervascularity without leak or inflammation in transgenic mice overexpressing hypoxia-inducible factor- $1 \alpha$. Genes \& Dev. 15: 2520-2532.

Ema, M., Hirota, K., Mimura, J., Abe, H., Yodoi, J., Sogawa, K., Poellinger, L., and Fujii-Kuriyama, Y. 1999. Molecular mechanisms of transcription activation by HLF and HIF $1 \alpha$ in response to hypoxia: Their stabilization and redox signalinduced interaction with CBP/p300. EMBO J. 18: 1905-1914.

Epstein, A.C.R., Gleadle, J.M., McNeil, L.A., Hewitson, K.S., O'Rourke, J., Mole, D.R., Mukherji, M., Metzen, E., Wilson, M.I., Dhanda, A., et al. 2001. C. elegans EGL-9 and mammalian homologs define a family of dioxygenases that regulate HIF by prolyl hydroxylation. Cell 107: 43-54.

Erez, N., Milyavsky, M., Goldfinger, N., Peles, E., Gudkov, A.V., and Rotter, V. 2002. Falkor, a novel cell growth regulator isolated by a functional genetic screen. Oncogene 21: 6713-6721.

Freedman, S.J., Sun, Z.Y., Poy, F., Kung, A.L., Livingston, D.M., Wagner, G., and Eck, M.J. 2002. Structural basis for recruitment of $\mathrm{CBP} / \mathrm{p} 300$ by hypoxia-inducible factor- $1 \alpha$. Proc. Nat1. Acad. Sci. 99: 5367-5372.

Goldberg, M.A., Dunning, S.P., and Bunn, H.F. 1988. Regulation of the erythropoietin gene: Evidence that the oxygen sensor is a heme protein. Science 242: 1412-1415.

Graeber, T.G., Osmanian, C., Jacks, T., Housman, D.E., Koch, C.J., Lowe, S.W., and Giaccia, A.J. 1996. Hypoxia-mediated selection of cells with diminished apoptotic potential in solid tumours. Nature 379: 88-91.

Groulx, I. and Lee, S. 2002. Oxygen-dependent ubiquitination and degradation of hypoxia-inducible factor requires nuclear-cytoplasmic trafficking of the von Hippel-Lindau tumor suppressor protein. Mol. Cell. Biol. 22: 5319-5336.

Gu, J., Milligan, J., and Huang, L.E. 2001. Molecular mechanism of hypoxia-inducible Factor 1-p300 interaction. J. Biol. Chem. 276: 3550-3554.

Gu, Y.Z., Moran, S.M., Hogenesch, J.B., Wartman, L., and Brad- field, C.A. 1998. Molecular characterization and chromosomal localization of a third $\alpha$-class hypoxia inducible factor subunit, HIF3 $\alpha$. Gene Expr. 7: 205-213.

Heidbreder, M., Fröhlich, F., Jöhren, O., Dendorfer, A., Qadri, F., and Dominiak, P. 2003. Hypoxia rapidly activates HIF-3 $\alpha$ mRNA expression. FASEB J. 17: 1541-1543.

Hewitson, K.S., McNeill, L.A., Riordan, M.V., Tian, Y.M., Bullock, A.N., Welford, R.W., Elkins, J.M., Oldham, N.J., Bhattacharya, S., Gleadle, J.M., et al. 2002. Hypoxia-inducible factor (HIF) asparagine hydroxylase is identical to factor inhibiting HIF (FIH) and is related to the cupin structural family. J. Biol. Chem. 277: 26351-26355.

Hirsila, M., Koivunen, P., Gunzler, V., Kivirikko, K.I., and Myllyharju, J. 2003. Characterization of the human prolyl 4-hydroxylases that modify the hypoxia-inducible factor HIF. $J$. Biol. Chem. 278: 30772-30780.

Hofer, T., Desbaillets, I., Hopfl, G., Gassmann, M., and Wenger, R.H. 2001. Dissecting hypoxia-dependent and hypoxia-independent steps in the HIF-1 $\alpha$ activation cascade: Implications for HIF-1a gene therapy. FASEB J. 15: 2715-2717.

Hon, W.-C., Wilson, M.I., Harlos, K., Claridge, T.D.W., Schofield, C.J., Pugh, C.W., Maxwell, P.H., Ratcliffe, P.J., Stuart, D.I., and Jones, E.Y. 2002. Structural basis for the recognition of hydroxyproline in HIF- $1 \alpha$ by pVHL. Nature 417: 975-978.

Huang, L.E., Gu, J., Schau, M., and Bunn, H.F. 1998. Regulation of hypoxia-inducible factor $1 \alpha$ is mediated by an $\mathrm{O}_{2}$-dependent degradation domain via the ubiquitin-proteasome pathway. Proc. Nat1. Acad. Sci. 95: 7987-7992.

Huang, J., Zhao, Q., Mooney, S.M., and Lee, F.S. 2002. Sequence determinants in hypoxia inducible factor- $1 \alpha$ for hydroxylation by the prolyl hydroxylases PHD1, PHD2, and PHD3. J. Biol. Chem. 277: 39792-39800.

Isaacs, J.S., Jung, Y.J., Mimnaugh, E.G., Martinez, A., Cuttitta, F., and Neckers, L.M. 2002. Hsp90 regulates a von Hippel Lindau-independent hypoxia-inducible factor-1 $\alpha$-degradative pathway. J. Biol. Chem. 277: 29936-29944.

Ivan, M., Kondo, K., Yang, H., Kim, W., Valiando, J., Ohh, M., Salic, A., Asara, J.M., Lane, W.S., and Kaelin, W.G. 2001. $\mathrm{HIF} \alpha$ targeted for VHL-mediated destruction by proline hydroxylation: Implications for $\mathrm{O}_{2}$ sensing. Science 292: 464 468.

Ivan, M., Haberberger, T., Gervasi, D.C., Michelson, K.S., Gunzler, V., Kondo, K., Yang, H., Sorokina, I., Conaway, R.C., Conaway, J.W., et al. 2002. Biochemical purification and pharmacological inhibition of a mammalian prolyl hydroxylase acting on hypoxia-inducible factor. Proc. Natl. Acad. Sci. 99: 13459-13464.

Jaakkola, P., Mole, D.R., Tian, Y.-M., Wilson, M.I., Gielbert, J., Gaskell, S.J., von Kriegsheim, A., Hebestreit, H.F., Mukherji, M., Schofield, C.J., et al. 2001. Targeting of HIF- $\alpha$ to the von Hippel-Lindau ubiquitylation complex by $\mathrm{O}_{2}$-regulated prolyl hydroxylation. Science 292: 468-472.

Jain, S., Maltepe, E., Lu, M.M., Simon, C., and Bradfield, C.A. 1998. Expression of ARNT, ARNT2, HIF1 $\alpha, \mathrm{HIF} 2 \alpha$ and Ah receptor mRNAs in the developing mouse. Mech. Dev. 73: 117-123.

Jeong, J.-W., Bae, M.-K., Ahn, M.-Y., Kim, S.-H., Sohn, T.-K., Bae, M.-H., Yoo, M.-A., Song, E.J., Lee, K.-J., and Kim, K.-W. 2002. Regulation and destabilization of HIF- $1 \alpha$ by ARD1mediated acetylation. Cell 111: 709-720.

Jiang, B.H., Rue, E., Wang, G.L., Roe, R., and Semenza, G.L. 1996a. Dimerization, DNA binding, and transactivation properties of hypoxia-inducible factor 1. J. Biol. Chem. 271: 17771-17778.

Jiang, B.H., Semenza, G.L., Bauer, C., and Marti, H.H. 1996 b. 
Hypoxia-inducible factor 1 levels vary exponentially over a physiologically relevant range of $\mathrm{O}_{2}$ tension. Am. J. Physiol. 271: C1172-C1180.

Jiang, B.H., Zheng, J.Z., Leung, S.W., Roe, R., and Semenza, G.L. 1997. Transactivation and inhibitory domains of hypoxiainducible factor $1 \alpha$. Modulation of transcriptional activity by oxygen tension. J. Biol. Chem. 272: 19253-19260.

Kallio, P.J., Okamoto, K., O’Brien, S., Carrero, P., Makino, Y., Tanaka, H., and Poellinger, L. 1998. Signal transduction in hypoxic cells: Inducible nuclear translocation and recruitment of the CBP/p300 coactivator by the hypoxia-inducible factor-1 $\alpha$. EMBO J. 17: 6573-6586.

Kallio, P.J., Wilson, W.J., O'Brien, S., Makino, Y., and Poellinger, L. 1999. Regulation of the hypoxia-inducible transcription factor $1 \alpha$ by the ubiquitin-proteasome pathway. I. Biol. Chem. 274: 6519-6525.

Kamura, T., Sato, S., Iwai, K., Czyzyk-Krzeska, M., Conaway, R.C., and Conaway, J.W. 2000. Activation of HIF $1 \alpha$ ubiquitination by a reconstituted von Hippel-Lindau (VHL) tumor suppressor complex. Proc. Natl. Acad. Sci. 97: 10430-10435.

Kivirikko, K.I. and Pihlajaniemi, T. 1998. Collagen hydroxylases and the protein disulfide isomerase subunit of prolyl 4-hydroxylases. In Advances in enzymology and related areas of molecular biology (ed. D.L. Purich), pp. 325-398. J. Wiley, New York.

Knowles, H.J., Raval, R.R., Harris, A.L., and Ratcliffe, P.J. 2003. Effect of ascorbate on the activity of hypoxia-inducible factor in cancer cells. Cancer Res. 63: 1764-1768.

Kung, A.L., Wang, S., Klco, J.M., Kaelin, W.G., and Livingston, D.M. 2000. Suppression of tumor growth through disruption of hypoxia-inducible transcription. Nat. Med. 6: 1335-1340.

Kuznetsova, A.V., Meller, J., Schnell, P.O., Nash, J.A., Ignacak, M.L., Sanchez, Y., Conaway, J.W., Conaway, R.C., and Czyzyk-Krzeska, M.F. 2003. von Hippel-Lindau protein binds hyperphosphorylated large subunit of RNA polymerase II through a proline hydroxylation motif and targets it for ubiquitination. Proc. Nat1. Acad. Sci. 100: 2706-2711.

Lando, D., Peet, D.J., Gorman, J.J., Whelan, D.A., Whitelaw, M.L., and Bruick, R.K. 2002a. FIH-1 is an asparaginyl hydroxylase enzyme that regulates the transcriptional activity of hypoxia-inducible factor. Genes \& Dev. 16: 1466-1471.

Lando, D., Peet, D.J., Whelan, D.A., Gorman, J.J., and Whitelaw, M.L. 2002b. Asparagine hydroxylation of the HIF transactivation domain: A hypoxic switch. Science 295: 858-861.

Lavista-LLanos, S., Centanin, L., Irisarri, M., Russo, D.M., Gleadle, J.M., Bocca, S.N., Muzzopappa, M., Ratcliffe, P.J., and Wappner, P. 2002. Control of the hypoxic response in Drosophila melanogaster by the basic helix-loop-helix PAS protein Similar. Mol. Cell Biol. 22: 6842-6853.

Lee, C., Kim, S.J., Jeong, D.G., Lee, S.M., and Ryu, S.E. 2003. Structure of human FIH-1 reveals a unique active site pocket and interaction sites for HIF-1 and von Hippel-Lindau. I. Biol. Chem. 278: 7558-7563.

Lieb, M.E., Menzies, K., Moschella, M.C., Ni, R., and Taubman, M.B. 2002. Mammalian EGLN genes have distinct patterns of mRNA expression and regulation. Biochem. Cell Biol. 80: 421-426.

Lipscomb, E.A., Sarmiere, P.D., and Freeman, R.S. 2001. SM-20 is a novel mitochondrial protein that causes caspase-dependent cell death in nerve growth factor-dependent neurons. $J$. Biol. Chem. 276: 5085-5092.

López-Barneo, J., Pardal, R., and Ortega-Sáenz, P. 2001. Cellular mechanisms of oxygen sensing. Annu. Rev. Physiol. 63: 259-287.

Mabjeesh, N.J., Willard, M.T., Harris, W.B., Sun, H.Y., Wang, R., Zhong, H., Umbreit, J.N., and Simons, J.W. 2003. Dibenzo- ylmethane, a natural dietary compound, induces HIF- $1 \alpha$ and increases expression of VEGF. Biochem. Biophys. Res. Commun. 303: 279-286.

Mahon, P.C., Hirota, K., and Semenza, G.L. 2001. FIH-1: A novel protein that interacts with HIF- $1 \alpha$ and VHL to mediate repression of HIF-1 transcriptional activity. Genes \& Dev. 15: $2675-2686$.

Makino, Y., Kanopka, A., Wilson, W.J., Tanaka, H., and Poellinger, L. 2002. Inhibitory PAS domain protein (IPAS) is a hypoxia-inducible splicing variant of the hypoxia-inducible factor-3 $\alpha$ locus. J. Biol. Chem. 277: 32405-32408.

Masson, N., Willam, C., Maxwell, P.H., Pugh, C.W., and Ratcliffe, P.J. 2001. Independent function of two destruction domains in hypoxia-inducible factor- $\alpha$ chains activated by prolyl hydroxylation. EMBO J. 20: 5197-5206.

Maxwell, P.H., Wiesener, M.S., Chang, G.W., Clifford, S.C., Vaux, E.C., Cockman, M.E., Wykoff, C.C., Pugh, C.W., Maher, E.R., and Ratcliffe, P.J. 1999. The tumour suppressor protein VHL targets hypoxia-inducible factors for oxygendependent proteolysis. Nature 399: 271-275.

McNeill, L.A., Hewitson, K.S., Claridge, T.D., Seibel, J.F., Horsfall, L.E., and C.J., S. 2002. Hypoxia-inducible factor asparaginyl hydroxylase (FIH-1) catalyses hydroxylation at the $\beta$-carbon of asparagine-803. Biochem J. 367: 571-575.

Metzen, E., Berchner-Pfannschmidt, U., Stengel, P., Marxsen, J.H., Stolze, I., Klinger, M., Huang, W.Q., Wotzlaw, C., Hellwig-Burgel, T., Jelkmann, W., et al. 2003. Intracellular localization of human HIF- $1 \alpha$ hydroxylases: Implications for oxygen sensing. J. Cell Sci. 116: 1319-1326.

Min, J.-H., Yang, H., Ivan, M., Gertler, F., Kaelin Jr., W.G., and Pavletich, N. 2002. Structure of an HIF- $1 \alpha-$ pVHL complex: Hydroxyproline recognition in signaling. Science 296: 18861889.

Minet, E., Mottet, D., Michel, G., Roland, I., Raes, M., Remacle, J., and Michiels, C. 1999. Hypoxia-induced activation of HIF1: Role of HIF-1 $\alpha-H s p 90$ interaction. FEBS Lett. 460: 251256.

Moschella, M.C., Menzies, K., Tsao, L., Lieb, M.E., Kohtz, J.D., Kohtz, D.S., and Taubman, M.B. 1999. SM-20 is a novel growth factor-responsive gene regulated during skeletal muscle development and differentiation. Gene Expr. 8: 5966.

Oehme, F., Ellinghaus, P., Kolkhof, P., Smith, T.J., Ramakrishnan, S., Hütter, J., Schramm, M., and Flamme, I. 2002. Overexpression of PH-4, a novel putative proline 4-hydroxylase, modulates activity of hypoxia-inducible transcription factors. Biochem. Biophys. Res. Commun. 296: 343-349.

Ohh, M., Park, C.W., Ivan, M., Hoffman, M.A., Kim, T.-Y., Huang, L.E., Pavletich, N., Chau, V., and Kaelin, W.G. 2000. Ubiquitination of hypoxia-inducible factor requires direct binding to the $\beta$-domain of the von Hippel-Lindau protein. Nat. Cell Biol. 2: 423-427.

O'Rourke, J.F., Tian, Y.M., Ratcliffe, P.J., and Pugh, C.W. 1999. Oxygen-regulated and transactivating domains in endothelial PAS protein 1: Comparison with hypoxia-inducible factor-1 $\alpha$. J. Biol. Chem. 274: 2060-2071.

Park, S.K., Dadak, A.M., Haase, V.H., Fontana, L., Giaccia, A.J., and Johnson, R.S. 2003. Hypoxia-induced gene expression occurs solely through the action of hypoxia-inducible factor $1 \alpha$ (HIF-1 $\alpha$ ): Role of cytoplasmic trapping of HIF-2a. Mol. Cell. Biol. 23: 4959-4971.

Pugh, C.W., O'Rourke, J.F., Nagao, M., Gleadle, J.M., and Ratcliffe, P.J. 1997. Activation of hypoxia-inducible factor-1; definition of regulatory domains within the $\alpha$ subunit. $I$. Biol. Chem. 272: 11205-11214. 
Salceda, S. and Caro, J. 1997. Hypoxia-inducible factor 1a (HIF1a) protein is rapidly degraded by the ubiquitin-proteasome system under normoxic conditions. Its stabilization by hypoxia depends on redox-induced changes. J. Biol. Chem. 272: 22642-22647.

Sang, N., Fang, J., Srinivas, V., Leshchinsky, I., and Caro, J. 2002. Carboxyl-terminal transactivation activity of hypoxia-inducible factor $1 \alpha$ is governed by a von-Hippel-Lindau protein-independent, hydroxylation-regulated association with p300/CBP. Mol. Cell. Biol. 22: 2984-2992.

Schlemminger, I., Mole, D.R., McNeill, L.A., Dhanda, A., Hewitson, K.S., Tian, Y.M., Ratcliffe, P.J., Pugh, C.W., and Schofield, C.J. 2003. Analogues of dealanylalahopcin are inhibitors of human HIF prolyl hydroxylases. Bioorg. Med. Chem. Lett. 13: 1451-1454.

Schroedl, C., McClintock, D.S., Budinger, G.R., and Chandel, N.S. 2002. Hypoxic but not anoxic stabilization of HIF-1 $\alpha$ requires mitochondrial reactive oxygen species. Am. J. Physiol. Lung Cell. Mol. Physiol. 283: L922-L931.

Schumacker, P.T. 2002. Hypoxia, anoxia, and $\mathrm{O}_{2}$ sensing: The search continues. Am. J. Physiol. Lung Cell. Mol. Physiol. 283: L918-L921.

Semenza, G.L. 2000. HIF-1 and human disease: One highly involved factor. Genes \& Dev. 14: 1983-1991.

- 2002. HIF-1 and tumor progression: Pathophysiology and therapeutics. Trends Mol. Med. 8: S62-S67.

Sowter, H.M., Ratcliffe, P.J., Watson, P., Greenberg, A.H., and Harris, A.L. 2001. HIF-1-dependent regulation of hypoxic induction of the cell death factors BNIP3 and NIX in human tumors. Cancer Res. 61: 6669-6673.

Srinivas, V., Zhang, L.P., Zhu, X.H., and Caro, J. 1999. Characterization of an oxygen/redox-dependent degradation domain of hypoxia-inducible factor $\alpha$ (HIF- $\alpha)$ proteins. Biochem. Biophys. Res. Comm. 260: 557-561.

Stroka, D.M., Burkhardt, T., Desbaillets, I., Wenger, R.H., Neil, D.A., Bauer, C., Gassmann, M., and Candinas, D. 2001. HIF-1 is expressed in normoxic tissue and displays an organspecific regulation under systemic hypoxia. FASEB $I$. 15: 2445-2453.

Tanimoto, K., Makino, Y., Pereira, T., and Poellinger, L. 2000. Mechanism of regulation of the hypoxia-inducible factor- $1 \alpha$ by the von Hippel-Lindau tumor suppressor protein. EMBO J. 19: 4298-4309.

Taylor, M.S. 2001. Characterization and comparative analysis of the EGLN gene family. Gene 275: 125-132.

Taylor, B.L. and Zhulin, I.B. 1999. PAS domains: Internal sensors of oxygen, redox potential, and light. Microbiol. Mol. Biol. Rev. 63: 479-506.

Tian, H., McKnight, S.L., and Russell, D.W. 1997. Endothelial PAS domain protein 1 (EPAS1), a transcription factor selectively expressed in endothelial cells. Genes \& Dev. 11: 72 82.

Trent, C., Tsung, N., and Horvitz, H.R. 1983. Egg-laying defective mutants of the nematode Caenorhabditis elegans. Genetics 104: 619-647.

Wang, G.L. and Semenza, G.L. 1995. Purification and characterization of hypoxia-inducible factor 1. J. Biol. Chem. 270: $1230-1237$.

Wang, G.L., Jiang, B.H., Rue, E.A., and Semenza, G.L. 1995a. Hypoxia-inducible factor 1 is a basic-helix-loop-helix-PAS heterodimer regulated by cellular $\mathrm{O}_{2}$ tension. Proc. Natl. Acad. Sci. 92: 5510-5514.

Wang, G.L., Jiang, B.H., and Semenza, G.L. 1995b. Effect of protein kinase and phosphatase inhibitors on expression of hypoxia-inducible factor 1. Biochem. Biophys. Res. Comm. 216: 669-675.
Warnecke, C., Griethe, W., Weidemann, A., Jurgensen, J.S., Willam, C., Bachmann, S., Ivashchenko, Y., Wagner, I., Frei, U., Wiesener, M., et al. 2003. Activation of the hypoxiainducible factor-pathway and stimulation of angiogenesis by application of prolyl hydroxylase inhibitors. FASEB $J$. 17: 1186-1188.

Wenger, R.H. 2002. Cellular adaptation to hypoxia: $\mathrm{O}_{2}$-sensing protein hydroxylases, hypoxia-inducible transcription factors, and $\mathrm{O}_{2}$-regulated gene expression. FASEB J. 16: 11511162.

Wiener, C.M., Booth, G., and Semenza, G.L. 1996. In vivo expression of mRNAs encoding hypoxia-inducible factor 1 . Biochem. Biophys. Res. Comm. 225: 485-488.

Wiesener, M.S., Turley, H., Allen, W.E., Willam, C., Eckardt, K.U., Talks, K.L., Wood, S.M., Gatter, K.C., Harris, A.L., Pugh, C.W., et al. 1998. Induction of endothelial PAS domain protein- 1 by hypoxia: Characterization and comparison with hypoxia-inducible factor-1 $\alpha$. Blood 92: 2260-2268.

Wiesener, M.S., Jürgensen, J.S., Rosenberger, C., Scholze, C.K., Hörstrup, J.H., Warnecke, C., Mandriota, S., Bechmann, I., Frei, U.A., Pugh, C.W., et al. 2003. Widespread hypoxia-inducible expression of HIF-2 $\alpha$ in distinct cell populations of different organs. FASEB J. 17: 271-273.

Willam, C., Masson, N., Tian, Y.M., Mahmood, S.A., Wilson, M.I., Bicknell, R., Eckardt, K.U., Maxwell, P.H., Ratcliffe, P.J., and Pugh, C.W. 2002. Peptide blockade of HIF $\alpha$ degradation modulates cellular metabolism and angiogenesis. Proc. Nat1. Acad. Sci. 99: 10423-10428.

Wright, G., Higgin, J.J., Raines, R.T., Steenbergen, C., and Murphy, E. 2003. Activation of the prolyl hydroxylase oxygensensor results in induction of GLUT1, heme oxygenase-1, and nitric-oxide synthase proteins and confers protection from metabolic inhibition to cardiomyocytes. J. Biol. Chem. 278: 20235-20239.

Yu, F., White, S.B., and Lee, F.S. 2001. HIF- $1 \alpha$ binding to VHL is regulated by stimulus-sensitive proline hydroxylation. Proc. Nat1. Acad. Sci. 98: 9630-9635.

Zelzer, E., Wappner, P., and Shilo, B.Z. 1997. The PAS domain confers target gene specificity of Drosophila bHLH/PAS proteins. Genes \& Dev. 11: 2079-2089. 


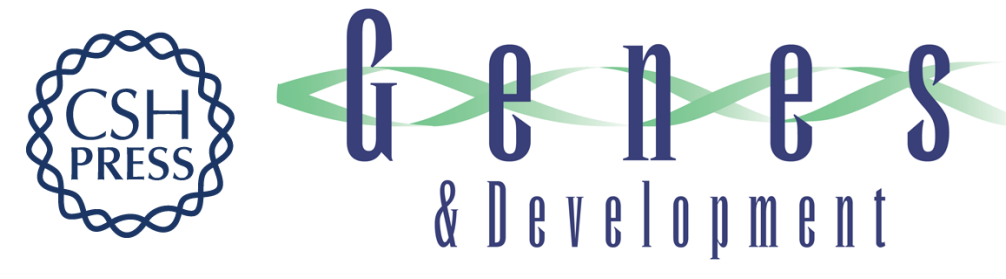

\section{Oxygen sensing in the hypoxic response pathway: regulation of the hypoxia-inducible transcription factor}

Richard K. Bruick

Genes Dev. 2003, 17:

Access the most recent version at doi:10.1101/gad.1145503

References This article cites 97 articles, 61 of which can be accessed free at: http://genesdev.cshlp.org/content/17/21/2614.full.html\#ref-list-1

License

Email Alerting

Receive free email alerts when new articles cite this article - sign up in the box at the top Service right corner of the article or click here.

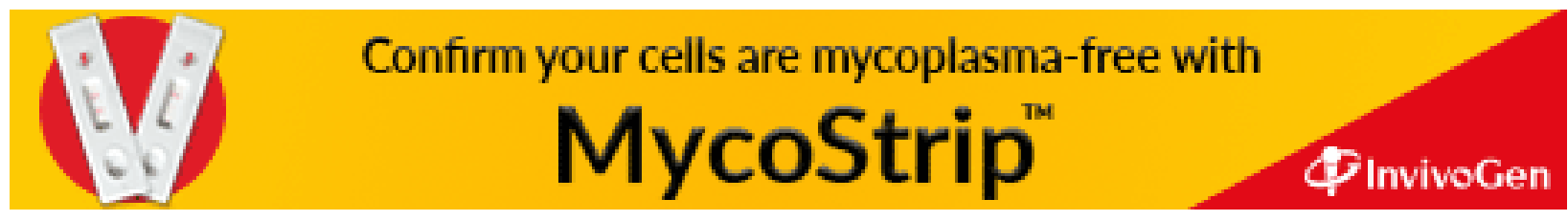

